\title{
灵国pubvet
}

https://doi.org/10.31533/pubvet.v15n03a767.1-11

\section{Carcinoma de células escamosas cutâneo em cães}

\section{Lucas Schneider $^{1}{ }^{\ominus}$, Luísa Mariano Cerqueira da Silva ${ }^{1} \bullet \mathbb{D}$, Bruna Daniela dos Santos Valle $^{1 \bullet}$,

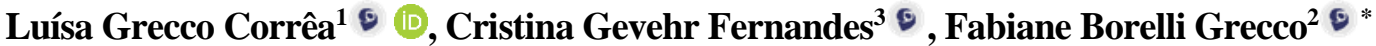

${ }^{1}$ Programa de Pós-Graduação em Veterinária/UFPEL. Pelotas, Rio Grande do Sul, Brasil

${ }^{2}$ Professora associada - Departamento de Patologia Animal/UFPEL. Pelotas, Rio Grande do Sul, Brasil

${ }^{3}$ Professora Titular - Departamento de Patologia Animal/UFPEL. Pelotas, Rio Grande do Sul, Brasil

*Autor para correspondência, E-mail: fabianegrecco18@gmail.com

Resumo. O carcinoma de células escamosas (CCE) é um neoplasma cutâneo maligno originário dos queratinócitos. Sua casuística é muito comum na clínica de animais de companhia e o médico veterinário deve ter amplo conhecimento a respeito de como esta enfermidade se comporta e evolui para evitar o comprometimento da vida de seus pacientes. $O$ presente estudo teve como objetivo realizar uma revisão bibliográfica sobre o carcinoma de células escamosas cutâneo na espécie canina. Foram levados em consideração dados relevantes a respeito da etiopatogenia do CCE (radiação ultravioleta, infecção por herpesvírus, perda de moléculas de adesão celular e imunossupressão), da epidemiologia, dos sinais clínicos, da macroscopia, das características microscópicas dos subtipos tumorais (bem-diferenciado, diferenciado e indiferenciado), da graduação histopatológica (grau I, II e III), do diagnóstico, do prognóstico, do tratamento e da prevenção.

Palavras-chave: Cães, histopatologia, patologia veterinária

\section{Cutaneous squamous cell carcinoma in dogs}

Abstract. Squamous cell carcinoma (SCC) is a malignant cutaneous neoplasm originated from keratinocytes. Its casuistry is very common in the pet clinic and the veterinarian must have ample knowledge about how this disease behaves and evolves to avoid compromising the lives of his patients. The present study aimed to conduct a bibliographic review on cutaneous squamous cell carcinoma in the canine species. Relevant data were taken into account regarding the etiopathogenesis of the CCE (ultraviolet radiation, herpesvirus infection, loss of cell adhesion molecules and immunosuppression), epidemiology, clinical signs, macro and microscopic signs of tumor subtypes (well-differentiated, differentiated and undifferentiated), histopathological graduation (grades I, II and III), diagnosis, prognosis, treatment and prevention.

Keywords: Dogs, histopathology, veterinary pathology

\section{Carcinoma cutáneo de células escamosas en perros}

Resumen. El carcinoma de células escamosas (SCC) es una neoplasia cutánea maligna que se origina en los queratinocitos. Su casuística es muy común en la clínica de mascotas y el veterinario debe tener un amplio conocimiento sobre cómo se comporta y evoluciona esta enfermedad para evitar comprometer la vida de sus pacientes. El presente estudio tuvo como objetivo realizar una revisión bibliográfica sobre el carcinoma cutáneo de células escamosas en las especies caninas. Se tomaron en cuenta datos relevantes con respecto a la etiopatogenia del SCC (radiación ultravioleta, infección por herpesvirus, pérdida de moléculas de adhesión celular e inmunosupresión), epidemiología, signos clínicos, 
macroscopia, características microscópicas de los subtipos de tumor (bien diferenciados, diferenciado e indiferenciado), graduación histopatológica (grados I, II y III), diagnóstico, pronóstico, tratamiento y prevención.

Palabras clave: Histopatología, patología veterinaria, perros

\section{Introdução}

O câncer é caracterizado pelo crescimento celular descoordenado e persistente, sendo o resultado de inúmeras alterações genéticas que ocorrem nas células e levam a alterações no equilíbrio entre a proliferação e a morte celular programada. A suscetibilidade ao câncer é determinada pela interação de fatores genéticos, dietéticos, infecciosos, ambientais e ocupacionais a agentes cancerígenos (Almeida et al., 2005; Cardona et al., 2013).

A pele por ser um órgão de grande extensão, acaba ficando exposto a uma grande quantidade de agentes carcinogênicos. Ela é composta pela epiderme, pela derme, anexos epidérmicos (glândulas sebáceas, glândulas sudoríparas e folículos pilosos), nervos e vasos. Por apresentar uma grande variedade celular e alto índice de renovação, a pele esta suscetível a mutações, o que propicia o surgimento de neoplasias. Além da influência genética, os agentes físicos e químicos são os principais causadores das neoplasias. As neoplasias cutâneas estão entre as neoplasias mais frequentes nos caninos, representando aproximadamente 30\% das neoplasias na espécie (Collins et al., 2000; Daleck et al., 2016; Ettinger et al., 2002).

Os queratinócitos são as células mais abundantes da epiderme e estão em todos os seus estratos, sendo mais numerosos nos superficiais. O estrato córneo possui a maior quantidade destas células. Os desmossomos e os filamentos de queratina são importantes na coesão entre as células e na conferência de resistência ao atrito. A queratina produzida não é igual em todas as camadas, pois a composição se modifica à medida que os queratinócitos se diferenciam. Nas camadas mais próximas à derme, a queratina apresenta baixo pelo molecular visto que os queratinócitos são menos diferenciados. Os queratinócitos no estrato córneo formam placas sem vida que continuamente descamam (Junqueira \& Carneiro, 2013).

O carcinoma de células escamosas (CCE) é um neoplasma cutâneo maligno originário dos queratinócitos e comum nos animais de companhia (Huppes et al., 2014; Nagamine et al., 2017; Teixeira et al., 2010; Tillmann et al., 2017). O comportamento biológico do CCE é localmente invasivo para a derme e tecidos subcutâneos adjacentes. Ele apresenta crescimento lento e potencialmente metastático.

Os principais locais de metástase são os linfonodos regionais, os ossos e os pulmões (Mineshige et al., 2018; Tillmann et al., 2017). O CCE é responsável por 4\% a 10\% de todas as neoplasias de pele na espécie canina (Daleck et al., 2016; Willcox et al., 2019).

Com os avanços da oncologia veterinária, é exigido do médico veterinário estar sempre atualizado e possuir uma base sólida de conhecimento sobre o assunto. Baseado nisto, a presente revisão bibliográfica tem como objetivo principal reunir informações atuais sobre o carcinoma de células escamosas cutâneo em cães, com a abordagem focada no ponto de vista clínico e patológico.

\section{Etiopatogenia}

\section{Radiação ultravioleta}

Devido a sua posição geográfica, o Brasil sofre influência das alterações na camada de ozônio, recebendo altas concentrações de radiação ultravioleta (UV), o que torna o CCE frequente na clínica de pequenos animais visto que esta radiação é um dos principais fatores ligados a iniciação e ao desenvolvimento dessa neoplasia (De Nardi et al., 2002).

As reações fotoquímicas geradas pela radiação ativam vias inflamatórias, alteram o sistema imune e lesam diretamente o DNA. Esses eventos terminam por não permitir o adequado reparo do DNA e causam mutações nos genes reguladores (p53 e p16), facilitando a expansão clonal das células cancerígenas (Ettinger et al., 2002). Além dos efeitos sobre o DNA, os raios ultravioletas podem causar efeito imunossupressor direto sobre as células de Langherans (células apresentadoras de antígenos na 
epiderme e que atuam como sentinelas do sistema imunológico) influenciando assim no aumento da produção de citocinas cutâneas (Collins et al., 2000; Rosolem et al., 2012).

$\mathrm{O}$ estresse fotoxidativo provocado por raios UVA causa mutações no DNA indiretamente, e a radiação UVB age diretamente na formação de dímero de timina e transições $\mathrm{C} \rightarrow \mathrm{T}$ OU $\mathrm{CC} \rightarrow \mathrm{TT}$ no DNA e RNA. A ausência de mecanismos de reparação nessas alterações representa o início das mutações dos queratinócitos, que podem progredir para a queratose actínica (Stockfleth \& Kerl, 2006). A queratose actínica é a proliferação pré-maligna dos queratinócitos epidérmicos em cães expostos a luz solar (Meuten, 2002).

\section{Papilomavírus}

Os papilomavírus (PV) são vírus pequenos e sem envelope com uma fita dupla circular de DNA capazes de infectar mamíferos, aves e répteis. Por não apresentar envelope viral, os PV são resistentes no meio ambiente. Eles são responsáveis por apresentações clínicas que variam desde assintomáticas até o desenvolvimento de lesões proliferativas benignas ou malignas no epitélio oral e cutâneo. Geralmente as lesões ficam limitadas a uma localização no corpo. A maioria deles infecta a camada basal do epitélio estratificado e se replica exclusivamente nas células epiteliais, com um ciclo de vida regulado pela diferenciação celular (Altamura et al., 2016; Hoggard et al., 2018; Munday \& Kiupel, 2010; Thaiwong et al., 2018a).

Inicialmente, as partículas virais invadem as células da camada basal da epiderme através da ruptura do epitélio. A infecção inicial é seguida por um período de latência onde o genoma viral sofre várias replicações. Após a diferenciação das células basais no epitélio em maturação, ocorre a expressão dos genes do capsídeo, que levarão a produção do vírus maduro no organismo hospedeiro (Greene, 2006).

Os PV podem influenciar o crescimento e diferenciação celular, assim como induzir a transformação neoplásica dos queratinócitos infectados (Munday \& Kiupel, 2010). Eles atuam como cofatores junto aos raios UV na promoção das mutações nas células suscetíveis (Hufbauer \& Akgül, 2017). Assim como em felinos e humanos, nos caninos, os PV induzem a formação de placas virais que podem progredir para a formação de carcinomas in situ ou invasivos, principalmente em animais imunossuprimidos (Munday \& Kiupel, 2010).

Em humanos, a carcinogênese da infecção pelo papilomavírus humano (HPV) ocorre devido à inativação do gene supressor tumor p53 pelos oncogenes virais E6 e E7, resultando em perda do controle do ciclo celular, diferenciação celular prejudicada, mutações aumentadas, alterações cromossômicas e instabilidade cromossomal (Favrot et al., 2009; Supsavhad et al., 2016; Thaiwong et al., 2018a). Essas células geneticamente instáveis se dividem rapidamente e acumulam mutações adicionais, resultando em progressão maligna (Doobar \& Sterling, 2001). Para o HPV estar associado ao CCE é necessário haver a evidência de DNA viral dentro do tumor, haver a transcrição de oncogenes virais ativos em células tumorais e haver a interação de oncoproteínas virais E6 e E7 com os genes supressores tumorais (Hoggard et al., 2018).

A proteína E6 inibe o programa de diferenciação normal dos queratinócitos. Os queratinócitos positivos para E7 apresentam alteração significativa na proliferação e diferenciação celular. As células perdem sua polaridade normal e ganharam a capacidade de invadir a matriz dérmica. À medida que a membrana basal é comprometida, ocorre a degradação do colágeno VII, do colágeno IV e da lamininaV (Hufbauer \& Akgül, 2017).

\section{Perdas das moléculas de adesão}

Em medicina humana, a perda de moléculas de adesão intercelular como a caderina-E, a $\beta$-catetina e a desmogleína estão relacionadas a um aumento da invasividade de células tumorais (Nagamine et al., 2017). O processo de invasão peritumoral consiste na separação das células tumorais, adesão aos componentes da matriz extracelular, proteólise do tecido adjacente e migração das células neoplásicas. As células epiteliais perdem suas moléculas de adesão e com isso a capacidade de coesão. O processo de invasão é seguido pela produção de várias proteinases que degradam as proteínas da matriz extracelular e da membrana basal (Patel \& Forsythe, 2011). 
A caderina-E é uma molécula de adesão celular típica em células epiteliais e o domínio intracitoplasmático de sua cauda terminal está ligada a filamentos de actina por proteínas citoplasmáticas chamadas cateninas. Dos três tipos de catetinas (alfa, beta e gama), a beta tem a função de formar o complexo caderina-E/ $\beta$-catetina. A perda desse complexo desempenha um papel importante na progressão e metástase do CCE em humanos. A desmogleína é um componente glicoproteico da membrana do desmossomos (estrutura de adesão celular), e sua diminuição está associada com a progressão tumoral e aumento de sua malignidade (Nagamine et al., 2017).

\section{Transição epitelial-mesenquimal}

A conversão de queratinócitos normais em células cancerígenas induz uma transição epitelialmesenquimal (TEM) associada à alteração nas moléculas de adesão celular que promovem o CCE e são necessárias para sua progressão. As características definidoras da TEM são a perda do fenótipo epitelial e aquisição de fenótipo mesenquimal, incluindo a atenuação da caderina-E e a aquisição da expressão de vimentina e caderina-N (Hufbauer \& Akgül, 2017; Mestrinho et al., 2015; Nagamine et al., 2017).

A TEM é formada por componentes celulares e extracelulares que envolvem as células tumorais em cada estágio da carcinogênese. Ela consiste de uma complexa rede de fibroblastos, células endoteliais, vasos sanguíneos e células imunes, juntamente com seus fatores secretados (citocinas, fatores de crescimento e componentes da matriz extracelular). A TEM também pode determinar o destino de células epiteliais disfuncionais, induzindo-as a continuar crescendo, a tornarem-se normais ou serem removidas (Wu et al., 2016).

A fibronectina, glicoproteína produzida pelos fibroblastos do tecido conjuntivo é importante para a adesão celular. Estudos mostram que a fibronectina é depositada em áreas peritumorais do CCE de pele humano positivo para HPV, e que estes poderiam ter sido produzidos e secretados por queratinócitos infectados e por fibroblastos estimulados por queratinócitos (Hufbauer \& Akgül, 2017).

Em modelos humanos e animais, a periostina é um elemento crítico do microambiente tumoral, pois contribui para o início da carcinogênese e da metástase, além de atuar como ligante para as integrinas e promover a motilidade e migração das células neoplásicas. No estudo de Mineshige et al. (2018) foi descoberto que a periostina é depositada intensamente no tecido estromal, particularmente na frente de invasão tumoral. Os fibroblastos parecem ser a principal fonte de periostina no CCE canino. O mesmo estudo sugeriu que o TGF- $\beta 1$ (fator beta de crescimento transformador 1 ) está associado à invasividade no CCE canino como fator indutor de periostina, ou seja, o TGF- $\beta 1$ derivado das células do CCE estimulam os fibroblastos a produzirem periostina, e esta pode promover a invasão de células cancerígenas.

A proteína p63 possui efeito homólogo a p53, e apresenta papel importante na regulação da adesão celular e sobrevivência de células epiteliais, promovendo a diferenciação e a proliferação das células cancerígenas quando diminuída (Mestrinho et al., 2015; Thaiwong et al., 2018a; Thaiwong et al., $\underline{2018 b})$.

\section{Imunossupressão}

Drogas imunossupressoras como a prednisolona, a ciclosporina, a azatioprina e o piroxicam estão sendo cada vez mais empregadas na clínica veterinária para o tratamento das mais variadas enfermidades. É possível que o uso abusivo destas drogas imunossupressoras possa contribuir para um aumento na incidência da transformação maligna das lesões associadas ao papilomavírus canino (Thaiwong et al., 2018b).

A ciclosporina e outros inibidores da calcineurina levam ao bloqueio da ação da proteína p53, aumentando o potencial tumorigênico (Papavasileiou et al., 2009). A azatioprina, um inibidor da síntese das purinas, aumenta a fotossensibilidade à luz UVA (incapaz de causar danos diretos ao DNA sozinha) e permite a lesão do DNA através do estresse oxidativo (Shulstad \& Proper, 2010).

\section{Epidemiologia}

Cães que apresentam a pelagem branca, olhos claros e pele pouco pigmentada apresentam um risco maior de desenvolver o carcinoma em relação aos outros animais com pele pigmentada. Cabeça, 
pescoço, períneo, dígitos, abdômen, membros torácicos e membros pélvicos são as regiões mais acometidas por esse neoplasma (Nagamine et al., 2017; Rosolem et al., 2012). Cães da raça American Pitt Bull Terrier, Basset Hound, Beagle, Boxer, Dachshund, Dálmata, Poodle, Scottish Terrier e animais sem raça definida (SRD) são predispostas ao desenvolvimento desta neoplasia (Daleck et al., 2016; Rosolem et al., 2012; Willcox et al., 2019).

O CCE inguinal ocorre principalmente na glande e prepúcio, sendo responsáveis por $95 \%$ das neoplasias malignas nessa região. A taxa metastática para esta localização anatômica é em torno de $25 \%$, sendo os linfonodos regionais os mais acometidos (Manesh et al., 2014). O CCE subungueal (sob a unha) é localmente invasivo e pode levar à lise óssea. Ele ocorre com maior frequência em caninos de porte grande e com pelagem escura como o Schnauzer gigante e geralmente acomete apenas um dígito (Daleck et al., 2016; Rosolem et al., 2012; Willcox et al., 2019).

\section{Sinais clínicos}

Os CCE se apresentam clinicamente na forma de escamas, de papilas ou de massas fungiformes, se estendendo de poucos milímetros a severos centímetros de diâmetro. Outros sinais clínicos mais frequentes são alopecia, eritema, adelgaçamento da epiderme, ulceração e descamação seguida da formação de crostas (Rosolem et al., 2012). Segundo Daleck et al. (2016), a queratose actínica pode estar associada ao hipotireoidismo, o que explicaria a necessidade de os caninos buscarem com mais intensidade a luz solar devido a termofilia que apresentam. Segundo Daleck et al. (2016), a maioria dos CCE associados com à radiação solar se desenvolvem como lesões múltiplas, frequentemente erosivas e ulceradas, podendo apresentar aspecto proliferativo e friável (semelhante à couve-flor).

Com a cronicidade, essas úlceras aumentam de tamanho e profundidade, ficando sujeitas às infecções bacterianas secundárias e a formação de exsudato purulento. Estas alterações podem estar presentes por longos períodos e geralmente estão associadas a ferimentos que não cicatrizam (Cardona et al., 2013; Rosolem et al., 2012; Tillmann et al., 2017).

Nos carcinomas das pálpebras, a conjuntivite é o principal sinal clínico. Epistaxe, espirros, aumento de volume, obstrução nasal, estertor e dispneia são os sinais mais comuns no CCE nasal (Daleck et al., 2016).

\section{Patologia}

\section{Macroscopia}

A queratose actínica (lesão inicial do CCE) costuma ser proliferativa, hiperêmica e crostosa. Pode haver a presença de inflamação, pápulas, máculas, comedões actínicos, nódulos queratóticos, crostas escurecidas, erosões, úlceras, elastose e fibrose solar. Essas lesões podem permanecer ativas formando crostas e descamando por muito tempo, inclusive anos (Cardona et al., 2013; Daleck et al., 2016; Tillmann et al., 2017; Withrow et al., 2020). As lesões são observadas nas áreas menos pigmentadas ou com menos pelos nos locais de maior exposição solar como abdômen ventral, lateral e flanco (Gross et al., 2008).

O carcinoma de células escamosas multicêntrico in situ em cães também pode se denominar Doença de Bowen ou doença bowenoide e está associado ao papilomavírus. As lesões da doença de Bowen podem ser crostosa ou verrucosas, solitárias ou múltiplas, alopécicas e/ou eritematosas. Pode ocorrer em áreas despigmentadas e pigmentadas, como face, dígitos, pescoço e membros torácicos (Daleck et al., 2016).

O CCE do tipo produtivo possui aspecto papilar de tamanho variável semelhante à "couve-flor", com a superfície ulcerada e de fácil sangramento. O tipo erosivo é o mais comum e é caracterizada por úlceras profundas que formam crateras e são cobertas por crostas (Fernandes, 2007). Ao corte, os tumores apresentam consistência firme, abrangência epidermo-dermal, aspecto regular compacto pouco delimitado e coloração esbranquiçada (Daleck et al., 2016; Rosolem et al., 2012).

\section{Microscopia}

Histologicamente, a queratose actínica apresenta hiperplasia, hiperqueratose, acantose e displasia dos queratinócitos que podem apresentar núcleos atípicos e aumentados, irregulares e hipercromáticos que não envolvem o estrato córneo, não invadindo a membrana basal. As lesões induzidas pela radiação UV 
podem levar a "elastose solar", causando degeneração e fragmentação do tecido elástico e das fibras de colágeno na superfície dermal (Boukamp, 2005; Hufbauer \& Akgül, 2017; Rosolem et al., 2012).

A doença de Bowen ou CCE in situ é semelhante aos CCE convencionais, diferindo por estar restrito a epiderme e ao folículo piloso, então, além da displasia, não há ruptura da membrana basal. Nele ocorre a perda de maturidade e polaridade dos queratinócitos, dando uma aparência desorganizada a epiderme ou "soprada pelo vento". Ele pode evoluir para CCE invasivo se não for tratado (Daleck et al., 2016; Johnson et al., 1992; Lee \& Wick, 1993).

O CCE bem-diferenciado se assemelha ao epitélio escamoso normal, com progressão ordenada de células basais poliédricas não queratinizadas na periferia da célula para grandes, poligonais e queratinizadas no centro da estrutura neoplásica. O CCE diferenciado apresenta pleomorfismo nuclear, aumento do número de mitoses e da queratinização, com presença de pérolas de queratina e infiltrado linfoplasmocitário (Cardona et al., 2013; Chacur et al., 2014; Nemec et al., 2012; Vitiello et al., 2017).

Quando indiferenciado, o CCE possui um predomínio de células imaturas com numerosas mitoses e pouca ou nenhuma queratinização, as células neoplásicas podem estar disseminadas e pequenos grupos ou como células únicas. Presença de pleomorfismo nuclear intenso muitas mitoses atípicas. Há um moderado infiltrado linfoplasmocitário misturado com neutrófilos, áreas necróticas dispersas e fibroplasia estromal (Cardona et al., 2013; Chacur et al., 2014; Nemec et al., 2012; Vitiello et al., 2017).

A desmoplasia é comumente associado a carcinomas invasivos. Nela ocorre à proliferação de tecido conjuntivo associado às células epiteliais neoplásicas invasoras. Essas células tumorais produzem moléculas sinalizadoras como fatores do crescimento, citocinas, hormônios e mediadores inflamatórios que estimulam os fibroblastos associados ao tumor a aumentarem sua produção de colágeno. A desmoplasia observada em CCE bem-diferenciados é de moderada a abundante enquanto que nos CCE pouco diferenciados a produção de colágeno estromal é menos intensa. A ocorrência de reação desmoplásica é significativa com o grau histológico (Daleck et al., 2016). Vale ressaltar que, segundo Tillmann et al. (2017), o subtipo tumoral não determina o estadiamento tumoral. Um CCE cutâneo indiferenciado pode apresentar um prognóstico favorável se o diagnóstico for precoce e o local anatômico da lesão permitir a exérese total com possibilidade de margens cirúrgicas livres.

\section{Graduação histopatológica}

A perda das moléculas de adesão intercelulares está associada com a invasividade das células tumorais e são úteis marcadores biológicos na avaliação do prognóstico no carcinoma de células escamosas cutâneo em humanos. Uma diminuição na expressão dessas moléculas no CCE cutâneo em cães é associada com o grau de queratinização, padrão de invasão, pleomorfismo nuclear e número de mitoses (Nagamine et al., 2017).

Para a realização do estadiamento tumoral, Nagamine et al. (2017) dividiu as cinco principais características morfológicas em escores. $O$ escore de queratinização 1 contava com alta queratinização (mais de 50\% das células queratinizadas), que diminuía para 20-50\%; 5-20\% e 0-5\% nos graus 2, 3 e 4 consecutivamente. O padrão de invasão variava de bem-delimitado com bordas infiltrativas no escore 1 para infiltrativo na forma de cordões sólidos e bandas; pequenos grupos ou cordas de células infiltrativas (mais de 15 células) e células dissociadas em pequenos grupos ou solitárias nos escores 2, 3 e 4 consecutivamente. A resposta inflamatória do hospedeiro variava de marcada no escore 1 para moderada, leve e ausente nos graus 2, 3 e 4 consecutivamente. $O$ grau de pleomorfismo nuclear variou de baixo (mais de $75 \%$ de células normais) no escore 1 para alto (menos de $25 \%$ de células normais) no escore 4. O número de mitoses também variou de 0-1 por campo no escore 1 até ser superior de 5 no escore 4. A soma desses escores classificou o CCE nos graus: I ( 6 a10 pontos), II ( 11 a 15 pontos) e III (16 a 20 pontos). Nagamine et al. (2017) avaliaram 58 casos de carcinomas de células escamosas cutâneo em caninos em seu estudo no Japão. Destes, 50\% $(\mathrm{n}=29)$ dos tumores foram classificados como grau I, apresentando grandes massas expansivas e com diferenciação semelhante ao estrato espinhoso da epiderme. Outros 25 animais (43\%) foram classificados como grau II, onde cresciam cordões de queratinócitos a partir da epiderme, com infiltração leve a moderada em linfócitos. Os outros 4 animais (7\%) foram classificados no grau III, onde havia a formação de arranjos infiltrativos e células tumorais isoladas, com pleomorfismo nuclear e ausência de queratinização. Com este estudo, os autores também 
provaram que ocorre a perda das moléculas de adesão intracelular à medida que o tumor se desenvolve, e que há um aumento da expressão das moléculas $\mathrm{N}$-caderina e vimentina.

\section{Diagnóstico}

É possível fazer um diagnóstico presuntivo de um tumor de pele pelo exame físico, pela inspeção e pela palpação da neoplasia. A análise hematológica e bioquímica geralmente não é útil para o diagnóstico dos tumores cutâneos, porém geram importantes informações sobre a condição clínica geral do paciente. A radiografia é útil para definir se há envolvimento ósseo ou dos linfonodos próximos devido à natureza altamente invasiva da neoplasia (Daleck et al., 2016). O diagnóstico definitivo é realizado pelo exame histopatológico juntamente com a anamnese e o exame físico (Huppes et al., 2014). Devido às características macroscópicas, deve ser realizado o diagnóstico diferencial de enfermidades fúngicas e bacterianas; lesões hiperplásicas, granulomatosas, inflamatórias e imunomediadas (Daleck et al., 2016; Tillmann et al., 2017).

Entres os diagnósticos diferenciais encontramos enfermidades como a leishmaniose, a esporotricose, a dermatofitose, o pênfigo e os processos alérgicos. O CCE deve ser diferenciado de outras neoplasias como o melanoma, o mastocitoma, o hemangioma, o hemangiossarcoma, o papiloma escamoso e o carcinoma basoescamoso (Rosolem et al., 2012).

\section{Tratamento}

O tratamento deve ser instituído de acordo com o estadiamento tumoral, o estado geral do paciente, a disponibilidade da medicação e dos equipamentos necessários, a aceitação do tutor em relação às mudanças estéticas e efeitos colaterais do tratamento. As principais opções de tratamento incluem a cirurgia, criocirurgia, radioterapia e quimioterapia (Rosolem et al., 2012). O diagnóstico precoce e o controle local efetivo podem conferir a cura do CCE. Os tratamentos cirúrgico e crioterápico são os mais indicados para os CCE devido à sua baixa capacidade metastática (Barros et al., 2008; Daleck et al., 2016).

\section{Cirurgia}

O tratamento cirúrgico tem como objetivo remover o tecido afetado pela neoplasia deixando as margens cirúrgicas livres de células neoplásicas, além de manter a estética e a função do tecido (Rogers, 1994). Nos casos de lesões solitárias da doença de Bowen, a exérese cirúrgica é recomendada, porém é comum que se originem novas lesões após o procedimento cirúrgico (Withrow et al., 2020). A excisão cirúrgica deve ser realizada com margens cirúrgicas de 1 a $3 \mathrm{~cm}$ de controle para evitar possíveis recidivas. Quando a margem cirúrgica não for possível, a cirurgia não é recomendada e deve-se optar por outros opções de tratamento (Daleck et al., 2016). Mesmo que acabe mutilando e comprometendo a estética do paciente, a intervenção cirurgia agressiva é a medida terapêutica mais eficaz e já foram relatados caninos com sobrevida de até quatro anos (Daleck et al., 2016).

\section{Criocirurgia}

Esta técnica consiste na destruição do tecido pelo uso controlado do congelamento e do descongelamento. A região é resfriada a $-20^{\circ} \mathrm{C}$, levando a morte celular através da formação de cristais de gelo intra e extracelulares. Esse processo é maximizado pelo congelamento rápido e descongelamento lento por três ciclos. Os produtos criogênicos mais utilizados são o nitrogênio líquido e o óxido nitroso (Thomson, 1990).

A criocirurgia é uma técnica segura, pouco cruenta e dificilmente desenvolve infecções secundárias. É um método não seletivo para o tecido saudável ou neoplásico, e acaba levando a edema, necrose e cicatrização por segunda intenção (Rosolem et al., 2012). Ela pode ser aplicada nos tumores superficiais não invasivos com áreas inferiores a $0,5 \mathrm{~cm}$ de diâmetro, nos casos em que o acesso cirúrgico não é indicado, quando não há área suficiente para a realização da sutura ou devido a não concordância do tutor com a cirurgia necessária. Esta modalidade é bem empregada nos casos pré-neoplásicos e no CCE in situ (Thomson, 1990). Não deve ser utilizada nas lesões superiores a $3 \mathrm{~cm}$ de diâmetro como terapia primária e nem quando esta pode retardar a ação de terapias mais efetivas (Barros et al., 2008; Rutteman \& Kirpensteinjn, 2003). 


\section{Quimioterapia}

A quimioterapia sistêmica pode ser utilizada com o objetivo de fornecer alívio paliativo para os caninos que apresentarem o CCE disseminado. No entanto, esta modalidade sistêmica se mostra pouco eficiente, com baixas taxas de resposta e curta sobrevida (Ferreira et al., 2006; Norsworthy et al., 2004). A doxorrubicina, a bleomicina, a cisplatina, a carboplatina, a actinomicina-D e anti-inflamatórios inibidores seletivos da COX-2 como o piroxican podem ser empregados como terapia adjuvante nos casos de CCE (Daleck et al., 2016; Ettinger et al., 2002). Segundo Daleck et al. (2016) pode-se utilizar carboplatina na dose de $250 \mathrm{mg} / \mathrm{m}^{2}$ a cada 21 dias, de 4 a 6 sessões ou a doxorrubicina na dose de 30 $\mathrm{mg} / \mathrm{m}^{2}$ também a cada 21 dias, de 4 a 6 sessões.

A quimioterapia intralesional é uma boa opção de tratamento para os casos onde a cirurgia convencional não consegue boas margens cirúrgicas. Esta modalidade oferece uma concentração elevada do fármaco na região e efeito prolongado da mesma. Os implantes empregados na terapia são constituídos de uma matriz proteica, um agente vasoativo como a epinefrina e o agente antineoplásico como a cisplatina e o 5-fluoruracil. O implante é bem tolerado pelos pacientes e as reações cutâneas ficam limitadas à área de aplicação e dificilmente geram reação sistêmica (Daleck et al., 2016; Rosolem et al., 2012). Segundo Daleck et al. (2016), a carboplatina na dose de $1,5 \mathrm{mg} / \mathrm{cm}^{3}$ a cada 7 dias até a remissão pode ser empregada para o tratamento intralesional.

\section{Radioterapia}

Ao contrário do que ocorre com a quimioterapia que atinge as células sadias, a radioterapia atinge apenas as células neoplásicas. Esta modalidade é utilizada para tumores primários e localizados, e quando a remoção cirúrgica não é possível. Regiões com grandes massas neoplásicas, profundas e invasivas são um exemplo de sua utilidade. A radioterapia ainda pode gerar um tempo de sobrevida de até um ano (Rosolem et al., 2012).

Daleck et al. (2016) recomendam que a radioterapia seja indicada como procedimento adjuvante nos casos onde a ressecção cirúrgica total com margens livres não é possível. Segundo Thomson (1990), as desvantagens desta técnica são a difícil disponibilidade de locais especializados, o custo e a necessidade de manter o animal sedado durante os procedimentos.

\section{Terapia fotodinâmica}

A fonte de luz empregada nesta terapia leva à formação de radicais livres através da associação de oxigênio molecular com uma fonte de luz. Estes radicais livres são citotóxicos às células proliferativas e levam a sua morte (Withrow et al., 2020). A associação do agente fotossensibilizador com a luz e o oxigênio molecular formam radicais livres que se acumulam nos tecidos lesados. Este acúmulo pode estar associado com a alteração na permeabilidade da membrana da célula tumoral, com as fibras colágenas imaturas e com os processos recentes de cicatrização (Rosolem et al., 2012).

Em relação à cirurgia, a terapia fotodinâmica produz menor lesão tecidual, não existe resistência ao fármaco e pode ser utilizado com outras terapias. É obrigatório que o animal fique em local escuro sem a exposição solar ao menos por duas semanas. Além da fotossensibilização, pode ocorrer edema facial, eritema e necrose secundária no local da aplicação (Rosolem et al., 2012).

\section{Prognóstico}

O prognóstico depende da localização e do estadiamento clínico na hora do diagnóstico. Os tumores com graus histológicos bem-diferenciados estão associados com um melhor prognóstico em relação aos pouco diferenciados. O prognóstico é favorável quando a excisão cirúrgica completa é possível ou quando o diagnóstico é precoce. Quando o CCE se encontra em estágios mais avançados e acometendo estruturas ósseas e linfonodos, o prognóstico se torna de reservado a desfavorável (Daleck et al., 2016; Rosolem et al., 2012). 


\section{Prevenção}

Os tutores de animais suscetíveis ao CCE devem restringir o acesso destes aos horários de maior radiação solar, que ocorrem entre as 10 e 16 horas (Patel \& Forsythe, 2011). As lesões iniciais regridem com o uso de fotoprotetores e da restrição solar, e, caso não regridam, pode-se utilizar roupas com filtro solar fator 30 ou superior, além de retirar o animal do contato com o sol (Patel \& Forsythe, 2011). O bloqueador solar é indicado a ser utilizado nas áreas sensíveis (plano nasal, orelhas e áreas glabras despigmentadas). Um filme protetor ultravioleta também pode ser utilizado nas janelas da casa para evitar o contato direto da radiação solar com a pele dos animais suscetíveis (Ettinger et al., 2002; Norsworthy et al., 2004; Rinker et al., 2001).

A hidratação da pele se mostra eficaz para evitar a progressão da doença. A utilização de xampus contendo ureia de 4 a $6 \%$ em banhos semanais ou de sprays para uso diário a base de ureia $3 \%$ e aloe vera $2 \%$ e de ampolas contendo ceramidas para uso semanal após o banho é uma boa opção (Patel \& Forsythe, 2011).

\section{Considerações finais}

A biópsia é essencial para o diagnóstico definitivo de CCE e para a sua classificação histopatológica. Medidas preventivas são de suma importância a fim de minimizar a possibilidade de recidiva e metástase.

\section{Referências}

Almeida, V. L., Leitão, A., Reina, L. del C. B., Montanari, C. A., Donnici, C. L., \& Lopes, M. T. P. (2005). Câncer e agentes antineoplásicos ciclo-celular específicos e ciclo-celular não específicos que interagem com o DNA: uma introdução. Química Nova, 28(1), 118-129. DOI: https://doi.org/10.1590/s0100-40422005000100021

Altamura, G., Corteggio, A., Pacini, L., Conte, A., Pierantoni, G. M., Tommasino, M., Accardi, R., \& Borzacchiello, G. (2016). Transforming properties of Felis catus papillomavirus type 2 E6 and E7 putative oncogenes in vitro and their transcriptional activity in feline squamous cell carcinoma in vivo. Virology, 496, 1-8. DOI: https://doi.org/10.1016/j.virol.2016.05.017

Barros, R. M., Jacobina, G. J., Ecco, R., Silva, C. E. V., \& Galera, P. D. (2008). Carcinoma das células escamosas multicêntrico em cão. Revista Brasileira de Saúde e Produção Animal, 9(1), 103-108.

Boukamp, P. (2005). Non-melanoma skin cancer: what drives tumor development and progression? Carcinogenesis, 26(10), 1657-1667. DOI: https://doi.org/10.1093/carcin/bgi123

Cardona, Á. J. A., Vargas, V. M. I., \& Perdomo, A. S. C. (2013). Clinical and histopathological study of the squamous cell carcinoma in cattle of the Cordoba Department, Colombia. Revista de La Facultad de Ciencias Veterinarias, 54(2), 68-77.

Chacur, M. G. M., Fachini, B. A., Yamasaki, L., Basso, K., Sanches, O. C., \& Pessoa, V. M. (2014). Carcinoma das células escamosas no prepúcio com invasão vertebral em equino. Semina: Ciências Agrárias, 35(3), 1383-1388. DOI: https://doi.org/10.5433/1679-0359.2014v35n3p1383

Collins, T., Cotran, R. S., \& Kumar, V. (2000). Patologia estrutural e funcional. Guanabara, Koogan.

Daleck, C. R., Fonseca, C. S., \& Canola, J. C. (2016). Oncologia em cães e gatos. Roca.

De Nardi, A. B., Rodaski, S., Sousa, R. S., Costa, T. A., Macedo, T. R., Rodigheri, S. M., Rios, A., \& Piekarz, C. H. (2002). Prevalência de neoplasias e modalidades de tratamentos em cães, atendidos no hospital veterinário da Universidade Federal do Paraná. Archives of Veterinary Science, 7(2), 15 26. DOI: https://doi.org/10.5380/avs.v7i2.3977

Doobar, J., \& Sterling, J. C. (2001). The biology of human papillomaviruses. In J. C. Sterling \& S. K. Tying (Eds.), Human papillomaviruses - clinical and scientific advances. Arnold.

Ettinger, S. J., Fedlman, E. C., \& Taibo, R. A. (2002). Tratado de medicina interna veterinaria: enfermedades del perro y el gato. Manole.

Favrot, C., Welle, M., Heimann, M., Godson, D. L., \& Guscetti, F. (2009). Clinical, histologic, and immunohistochemical analyses of feline squamous cell carcinoma in situ. Veterinary Pathology, 
46(1), 25-33. DOI: https://doi.org/10.1354/vp.46-1-25

Fernandes, C. G. (2007). Neoplasias em ruminantes e equinos. In F. Riet-Correa, S. A.L., L. R.A.A., \& B. J. R. J. (Eds.), Doenças de Ruminantes e Equídeos (pp. 650-656). Gráfica e Editora Pallotti.

Ferreira, I., Rahal, S. C., Ferreira, J., \& Corrêa, T. P. (2006). Terapêutica no carcinoma de células escamosas cutâneo em gatos. Ciência Rural, 36(3), 1027-1033. DOI: https://doi.org/10.1590/s0103$\underline{84782006000300051}$

Greene, C. E. (2006). Fatores ambientais de doenças infecciosas. In E. D. Ibid (Ed.), Doenças infecciosas em cães e gatos. Elsivier.

Gross, T. L., Ihrke, P. J., Walder, E. J., \& Affolter, V. K. (2008). Skin diseases of the dog and cat: clinical and histopathologic diagnosis. John Wiley \& Sons.

Hoggard, N., Munday, J. S., \& Luff, J. (2018). Localization of Felis catus papillomavirus type 2 E6 and E7 RNA in feline cutaneous squamous cell carcinoma. Veterinary Pathology, 55(3), 409-416. DOI: https://doi.org/10.1177/0300985817750456

Hufbauer, M., \& Akgül, B. (2017). Molecular mechanisms of human papillomavirus induced skin carcinogenesis. Viruses, 9(7), 187.

Huppes, R. R., Nardi, A. B., Uscategui, R. A. R., Pazzini, J. M., \& Castro, J. L. C. (2014). Nosectomia em felinos portadores de carcinoma espinocelular-Relato de sete casos. Semina: Ciências Agrárias, 35(2), 919-925. DOI: https://doi.org/10.5433/1679-0359.2014v35n2p919

Johnson, T. M., Rowe, D. E., Nelson, B. R., \& Swanson, N. A. (1992). Squamous cell carcinoma of the skin (excluding lip and oral mucosa). Journal of the American Academy of Dermatology, 26(3), 467484. DOI: https://doi.org/10.1016/0190-9622(92)70074-p

Junqueira, L. C., \& Carneiro, J. C. (2013). Histologia Básica (12 ed.). Guanabara Koogan.

Lee, M.-M., \& Wick, M. M. (1993). Bowen's disease. Clinics in Dermatology, 11(1), 43-46.

Manesh, J. Y. Y., Shafiee, R., Bahrami, A. M., Pourzaer, M., Pourzaer, M., Pedram, B., Javanbakht, J., Mokarizadeh, A., \& Khadivar, F. (2014). Cyto-histopathological and outcome features of the prepuce squamous cell carcinoma of a mixed breed dog. Diagnostic Pathology, 9(1), 1-7. DOI: https://doi.org/10.1186/s13000-016-0577-0

Mestrinho, L. A., Pissarra, H., Faisca, P. B., Braganca, M., Peleteiro, M. C., \& Niza, M. (2015). p63 and Ecadherin expression in canine oral squamous cell carcinoma. Veterinary Pathology, 52(4), 614-620.

Meuten, D. J. (2002). Tumors of the skin and soft tissues. Iowa Satate Press.

Mineshige, T., Ogihara, K., Kamiie, J., Sugahara, G., CHAMBERS, J. K., Uchida, K., Madarame, H., \& Shirota, K. (2018). Increased expression of the stromal fibroblast-secreted periostin in canine squamous cell carcinomas. Journal of Veterinary Medical Science, 80(3), 473-479. DOI: https://doi.org/10.1292/jvms.17-0647

Munday, J. S., \& Kiupel, M. (2010). Papillomavirus-associated cutaneous neoplasia in mammals. Veterinary Pathology, 47(2), 254-264. DOI: https://doi.org/10.1177/0300985809358604

Nagamine, E., Hirayama, K., Matsuda, K., Okamoto, M., Ohmachi, T., Uchida, K., Kadosawa, T., \& Taniyama, H. (2017). Invasive front grading and epithelial-mesenchymal transition in canine oral and cutaneous squamous cell carcinomas. Veterinary Pathology, 54(5), 783-791. DOI: https://doi.org/10.1177/0300985817707005

Nemec, A., Murphy, B., Kass, P. H., \& Verstraete, F. J. M. (2012). Histological subtypes of oral nontonsillar squamous cell carcinoma in dogs. Journal of Comparative Pathology, 147(2-3), 111-120. DOI: https://doi.org/10.1016/j.jcpa.2011.11.198

Norsworthy, G. D., Crystal, M. A., Grace, S. F., \& Tilley, L. P. (2004). O paciente felino. São Paulo: Roca, 3, 300.

Papavasileiou, D., Tosios, K., Christopoulos, P., Goutas, N., \& Vlachodimitropoulos, D. (2009). Her-2 immunohistochemical expression in oral squamous cell carcinomas is associated with polysomy of chromosome 17, not Her-2 amplification. Head and Neck Pathology, 3(4), 263. DOI: https://doi.org/10.1007/s12105-009-0134-1

Patel, A., \& Forsythe, P. J. (2011). Dermatologia em pequenos animais. Elsevier Brasil. 
Rinker, M. H., Fenske, N. A., Scalf, L. A., \& Glass, L. F. (2001). Histologic variants of squamous cell carcinoma of the skin. Cancer Control, 8(4), 354-363. DOI: https://doi.org/10.1177/107327480100800409

Rogers, K. S. (1994). Feline cutaneous squamous cell carcinoma. Feline Pract, 22(5), 7-9.

Rosolem, M. C., Moroz, L. R., \& Rodigheri, S. M. (2012). Carcinoma de células escamosas em cães e gatos: Revisão de literatura. PUBVET, 6, Art. 1295-1300.

Rutteman, G. R., \& Kirpensteinjn, J. (2003). Tumours of the mammary glands. In J. M. Dobson \& B. D. X. Lascelles (Eds.), Manual of canine and feline oncology (pp. 234-242). Gloucester: British Small Animal Veterinary Association.

Shulstad, R. M., \& Proper, S. (2010). Squamous cell carcinoma: a review of etiology, pathogenesis, treatment, and variants. Journal of the Dermatology Nurses' Association, 2(1), 12-16. DOI: https://doi.org/10.1097/jdn.0b013e3181cb5165

Stockfleth, E., \& Kerl, H. (2006). Guidelines for the management of actinic keratoses. European Journal of Dermatology, 16(6), 599-606.

Supsavhad, W., Dirksen, W. P., Martin, C. K., \& Rosol, T. J. (2016). Animal models of head and neck squamous cell carcinoma. The Veterinary Journal, 210, 7-16.

Teixeira, T. F., Silva, T. C. da, Cogliati, B., Nagamine, M. K., \& Dagli, M. L. Z. (2010). Retrospective study of melanocytic neoplasms in dogs and cats. Brazilian Journal of Veterinary Pathology, 3(2), 100-104.

Thaiwong, T., Sledge, D. G., Collins-Webb, A., \& Kiupel, M. (2018a). Immunohistochemical characterization of canine oral papillary squamous cell carcinoma. Veterinary Pathology, 55(2), 224232. DOI: https://doi.org/10.1177/0300985817741732

Thaiwong, T., Sledge, D. G., Wise, A. G., Olstad, K., Maes, R. K., \& Kiupel, M. (2018b). Malignant transformation of canine oral papillomavirus (CPV1)-associated papillomas in dogs: An emerging concern? Papillomavirus Research, 6, 83-89. DOI: https://doi.org/10.1016/j.pvr.2018.10.007

Thomson, R. G. (1990). Patologia veterinária especial (Vol. 1). Manole.

Tillmann, M. T., Felix, A. O. C., Fernandes, C. G., Oliveira Capella, S., Mueller, E. N., \& Nobre, M. O. (2017). Pacientes com carcinoma de células escamosas-relação do tratamento com o prognóstico. Acta Scientiae Veterinariae, 45, 5.

Vitiello, V., Burrai, G. P., Agus, M., Anfossi, A. G., Alberti, A., Antuofermo, E., Rocca, S., Cubeddu, T., \& Pirino, S. (2017). Ovis aries papillomavirus 3 in ovine cutaneous squamous cell carcinoma. Veterinary Pathology, 54(5), 775-782.

Willcox, J. L., Marks, S. L., Ueda, Y., \& Skorupski, K. A. (2019). Clinical features and outcome of dermal squamous cell carcinoma in 193 dogs (1987-2017). Veterinary and Comparative Oncology, 17(2), 130-138. DOI: https://doi.org/10.1111/vco.12461

Withrow, S. J., Page, R., \& Vail, D. M. (2020). Small animal clinical oncology. Elsevier Health Sciences.

Wu, T., Hong, Y., Jia, L., Wu, J., Xia, J., Wang, J., Hu, Q., \& Cheng, B. (2016). Modulation of IL-1 $\beta$ reprogrammes the tumor microenvironment to interrupt oral carcinogenesis. Scientific Reports, 6(1), 1-10. DOI: https://doi.org/10.1038/srep20208

Histórico:

Recebido: 18 de agosto de 2020 .

Aprovado: 14 de outubro de 2020.

Disponível online: 3 de dezembro de 2020.
Licenciamento: Este artigo é publicado na modalidade Acesso Aberto sob a licença Creative Commons Atribuição 4.0 (CC-BY 4.0), a qual permite uso irrestrito, distribuição, reprodução em qualquer meio, desde que o autor e a fonte sejam devidamente creditados. 